\title{
A visual art museum in Sweden as pedagogical scenery: Gibbs' reflective cycle guiding student nurses in the reflective process
}

\author{
Britt-Maj Wikström ${ }^{1,2}$ \\ ${ }^{1}$ Faculty of Health, Nutrition and Management, Oslo and Akershus University College, Oslo, Norway \\ ${ }^{2}$ Department of Public Health Sciences, Karolinska Institute, Stockholm, Sweden \\ Email: britt-maj@home.se
}

Received 9 March 2012; revised 17 April 2012; accepted 28 April 2012

\begin{abstract}
The pedagogy employed in health care education must continually be questioned and expanded. Student nurses must be prepared for nursing practice that continually changes, consequently alternative concepts in nurse education must be considered. The aims were to provide student nurses with reflection skills and to evaluate the potential of studying the reflective process using visual art at a museum as an enriched activity in education. A pedagogical program with Gibbs' reflection model was used as a complement. The study was conducted at a University College of Health Sciences in Sweden in collaboration with a visual art museum. Data were collected during a period of three years. A random sample ( $n=35$ of $n$ = 98 students' reports) was selected for qualitative analysis. The painting by George-Pierre Seurat, Seated woman was used as a source of inspiration. Analysis was conducted of the excerpts generated from the steps in Gibbs' reflection model and from students' evaluations of the teaching-learning structure. The results show that students were able to build hypothetical situations around the character depicted in the painting. They observed and described a great many aspects of the reflective process. The chosen painting was regarded as suitable for its purpose, and a source of inspiration. It could be interpreted as a patient you might meet in clinical practice. The students' evaluations show that they became aware of knowledge they had not thought of before, and a way of taking a step closer to clinical practice. It could be concluded that art museum could be regarded as a stimulating environment that nurtured the reflective process. Consequently, visual art museums have to be considered as possible teaching learning milieus to be used in nurse education. It is to be hoped that this study will contribute to further development of visual art museums as teaching learning settings.
\end{abstract}

Keywords: Student Nurses; Visual Art Museum; Education; Reflection; Works of Art

\section{INTRODUCTION}

It is necessary to acknowledge new and flexible ways to teach complex phenomena in nurse education. Nurse educators using paintings as a pedagogical instrument could make a vital contribution in teaching programs. In the present study the program at the museum focuses on Gibbs' [1,2] reflection model and visual art studied at the museum as complementary to theoretical knowledge in student nurse education.

Art as a pedagogical tool in nurse education has proven fruitful as an educative tool [See 1.3]. Aesthetic knowing adds a new dimension in nurse education that helps student nurses to use their personal knowledge and experiences. The notions of body language and facial expression are integrated into works of art. There are diversities in the aesthetic expressions that are invaluable sources in order to develop nurses' ability to understand nursing phenomena. Images from various situations in life enter into art. It is within the power of each person to share and interpret experiences by means of art, by viewing the work of others, and by using feelings and imagination and increasing the understanding of what the world has to offer as described by ancient philosophy and in philosophy of today [3-10]. The present study is an additional step to build up a pedagogical structure to be used at a museum which is an area that has to be further developed and investigated.

\subsection{Purpose of the Study}

The present study aimed at developing a pedagogical program with Gibbs' [2] reflection model as a complement in nurse education. Works of art at the museum were used as sources of inspiration to stimulate discussions about the reflection process. The questions that 
could be asked are whether students were able to construct hypothetical situations around the characters depicted in the painting. Which beneficial and/or non beneficial effects are registered from the students' points of view?

\subsection{Literature Review-The Implication of Art}

\section{Expressive Art Activities in Nursing-A Cure of Body and Mind}

The meaning of aesthetics has been formulated by ancient philosophers who saw a natural link between art and life. Painting, drama, dance and music were obvious parts of everyday life. They were regarded as a cure of body and mind. Humanistic functions of aesthetics could be described in words such as emotionality and intensity. They enlarge and intensify sensory experiences and offer sources of pleasure that cannot be experienced otherwise. [3-10]. A number of major humanistic functions of aesthetics in today's society are discussed. One function of aesthetics is that they help us to know ourselves and to become alive to human conditions. We are given a new way of looking at ourselves and the world. A painting, a piece of music invites us to participate in a new visual or auditory experience [11]. The alienation of art from the lives of ordinary people is an alienation from creativity. This alienation from our creativity may relate to negative messages given to us as children about artistic creativity [12].

The importance of aesthetics for physical and psychological health is to be found in nursing research of today. Visual art, music, dance and poetry are not isolated activities in nursing care, but are important parts of an entirety. The research describes how to use the different means of aesthetics for the benefit of the patient. Dialogues generated by visual art are connected to a positively perceived life situation and increased social interaction. Significant improvement was found in a visual art group compared to a matched control group [13-17]. Positive influence of cultural events, reading books and singing on perceived health has been reported $[18,19]$.

Music in nursing care is important and shows beneficial effects from the patients' perspective. Regular contact with a singer was a way to build a relationship with a child who was ill [20]. A group of children who listened to music during vein puncture perceived less pain compared to a control group [21]. Positive effect was found of music on perceived pain during wound dressing when the patients could choose their favourite music [22]. Music was used in long-term illness. Increased self-awaress and well-being were reported [23]. The effects of choir singing in a group of IBS persons were compared to a control group. Positive effects were found in the IBS group [24]. Positive effects of caregiver singing and background music on patients' emotions and moods were reported in dementia care and psycho geriatric care [25, 26]. Music was important to improve and promote sleep quality in older adults [27,28].

Hospital ward environment is important in the patient's healing process. Environmental enrichment with art prints was a meaningful complement to the healing process. It facilitates interaction between staff and patients. The patients regain a sense of control when they had the opportunity to select painting [29]. A research overview of the meaning of a healing environment shows that it contributes to a shortened healing time across multiple medical conditions [30].

\subsection{Arts as a Pedagogical Tool in Nurse Education}

The pedagogy employed in health care education must continually be questioned and expanded. Student nurses must be prepared for nursing practice that continually changes, meaning that alternative concepts in nurse education must be considered. Previous research into a variety of aesthetic forms of expressions such as music, poetry, and literature suggest that these could be used to develop nursing skills [31,32]. The understanding of health and illness were enhanced by the use of literature in nurse education [33]. The understanding caring through poetry, literature and painting captured experiences within a person's life. "Art can provide much of the context and learning necessary if students are to be able to relate their studies and practices to 'real people'." [34 p. 856] An educational tool with paintings was developed in order to complement theoretical knowledge regarding non-verbal communication. Students were able to infer whether a positive or negative message had been given to the depicted person [35]. Paintings were used to enhance observational competence, empathy, and interpersonal relations in nursing situations. The findings suggest that students observed, as well as described the painting according to formal aspects and easily transferred the role of the characters depicted in the painting to imaginary nursing situations [36-40]. The incorporation of aesthetic knowing into nursing education fosters caring and fluidity in practice, and expands the understanding of nursing practice [41]. Learning clinical observation skills at an art museum that involves observation, description, and interpretation of visual information could be developed [42]. Art gallery could offer a transformation of attitude, and a space that allows different kinds of thinking, or restores a sense of connecting with creative aspects of the self [43]. Works of art as an alternative pedagogical tool in nurse education has been investigated in a review study. It was concluded; the use of art adds a new dimension to student' experiences [44]. A 
pedagogical structure aimed to change attitudes of nursing students to a more positive view of elderly patients in long-term care. The pedagogical model involved the student and the patient in all steps from planning of cultural activity to completion of the activity [45]. Sacred art was used as a pedagogical tool in an experiment; Caravaggio's “The Calling of Saint Matthew” [46]. Art was used as a means to express and interpret emotions. It was found that different art forms in teaching develop trust and expression of emotion [47].

\section{METHOD}

\subsection{Procedure}

\section{Teaching Structure at the Art Museum}

The study was conducted in the students' second year at a University College of Health Sciences in Sweden. During a period of three years data were collected in the undergraduate program in the third term. In all, 98 students participated (age 19 - 34). From this group a random sample of 35 was selected for qualitative analysis.

\subsection{The Instructive Program Consists of the Following Steps}

At the nursing college;

1) Theoretical knowledge of the reflection process

2) How to use Gibbs reflection model

3) Introduction of the process at the museum; a teacher with knowledge in history of art introduced the students

At the museum;

4) The students received a short introduction by a curator (40 minutes) of some of the museums' paintings. This included observation and reflection on specific works of art

5) The students were encouraged to wander at will and enjoy the art works in small-groups (3 - 4). They were requested to look for aspects in works of art such as a meeting, and/or a relation between two or more persons from the perspective of reflection. The works of art at the museum are intended to provide the students a scene for a mental walk. Decisive for this adventure is the students' knowledge, fantasy and experiences together with the specific area to be studied. The role of the teacher is to support and encourage the students to get closer to the work of art and combine earlier memories and experiences with new impressions from the painting. The students own resources will be in focus.

6) The students were encouraged to discuss formal aspects in paintings, and consider why some of the paintings at the museum more than others captured their attention.

7) The students were asked to select one work of art of a pretested series of seven paintings with the same theme;
Edward Hopper, Western Motel, 1957, a woman in contemplation:

Caspar David Friedrich, Woman at window, 1822

Pierre Bonnard, Woman with a cat, 1912

Henri Matisse, Woman before an aquarium, 19211923

George-Pierre Seurat, Seated woman, 1883

George Braque, Position, 1942

Pablo Picasso, Portrait of woman, 1938

The selection of these paintings was performed on basis of methods in psychological and art scientific research into aesthetic reactions to and perception of art tendencies [48-50]. The set is supposed to indicate aesthetic preferences which may arise in an untrained spectator, who is not familiar with different art codes and interpretations [51,52]. The set has several dividing qualities like the degree of realism and mimetic, active or passive colour effects, degree of dramatic action, simple or complex form. The students work together in pairs. They were asked to choose one painting to be used for the reflection process. The series was pretested in a group of students $(\mathrm{n}=85)$ and George-Pierre Seurat, Seated woman was found to be suitable as initiator of reflection of a patient you might meet in clinical practice.

The students were asked to consider the following requests inspired by the painting George-Pierre Seurat, Seated woman:

Imagine a situation/meeting with a patient you remember fairly well!

Follow the steps in Gibbs model of reflection:

Feelings: What were you thinking and feeling?

Evaluation: What was good and bad about the experience?

Analysis: What sense can you make of the situation?

Conclusion: What else could you have done?

Action plan: If it is aroused again what would you do?

The answers to these steps were written down by each student group (2 - 3 students in each group). These written reports constitute data in this study.

\subsection{Data Analysis}

Analysis consists of participants' comments on how they use the painting as a source of inspiration for reflection with Gibbs' model [1]. The excerpts were analysed according to qualitative research [53]. The text was read carefully to gain an overview. Re-reading the text and searching the data for concepts relevant to experiences of student nurses. The next step was to search the descriptive codes, and finally developing themes from the codes. Rigor was achieved when a clear decision trail was followed. This meant that any reader or another researcher could follow the progression of events in the study and understand the logic and justification for what was done 
and why [54].

Validity was assured by quoting directly from the text and the connection of the interpretation to previous research in the area [55]. The literature was referenced in appropriate places. The researcher's cultural and linguistic understanding of the phenomenon is the prerequisite for coming to an understanding of participants' accounts. The excerpts have been translated into English by the author.

\subsection{Ethical Considerations}

Data collection followed the Helsinki declaration [56,57]. Qualities that are judged are ethical perspectives, the research design and the need in society for such a project. The purpose and procedure of the study were explained carefully to the participants, and they were ensured of confidentiality.

An ethical issue arising from student nurses' participation in the study is that the students are in a state of dependence on a teacher. However, the students' written reports were not graded.

\section{RESULTS}

Themes are presented according to the steps in Gibb's [1,2] reflection model: Feeling, evaluation, analysis, conclusion, and action plan.

\section{Feelings: What were you thinking and feeling?}

- ... to understand the patient's feelings without having the same feeling yourself ... empathy is about that ...

- ... she is depressed ... her body language and her facial expression ... her situation ...

- ... in my profession I need intuition ... how to understand the patients ... theory as well ...

- ... to understand that a less dramatic situation ... it might be a huge trauma for the patient ... you must always think of that ... always ...

- The imagined patient situation says something important ... I am not sure ... I have to think it over ... it might be ...

- ... we care for grieving and sad patients ... we need to give the patient some hope ... to feel less misery.

- An unpleasant feeling ... it is difficult to meet a patient in her grieving process ...

Evaluation: What was good and/or bad about the experience?

- It was interesting and useful to try to find out what a patient was thinking ... worried about ... from her body language.

- It became clear that you need intuition ... and experience ... not enough with theory ... but an important complement ...

- Your memory ... previous knowledge ... well-remembered situations ... finally interpret how to help a patient.

- You get new thoughts to reflect over ... from the "patient".

- You get a first impression ... then after some time you have to change the first impression ... an important experience.

- ... the "patient" helped me to understand the consequence of reflection ...

- ... you learn to analyze ... think more over the situation ... to pull together enough information ...

Analysis: What sense can you make of the situation?

- ... the patient needs to feel that she have some power over the situation ... despite she is at a hospital ... show consideration for the patient ...

- ... the patient might not understand the situation ... help the patient understand ...

- ... you can never take a situation for granted ... think it over

- ... your own feelings and thoughts is the base for how you reflect ... together with information from the "patient" ...

- ... to treat all patients respectfully ... make sure you understand the patient ...

- to bring to a halt and think ... do I use my time in an appropriate manner ...

\section{Conclusion: What else could you have done?}

- You could go deeper into the situation ... reflect of the situation ... collect more information from the "patient”...

- ... encourage patients to take their own initiative ... stimulate the patient ... give the patient alternative ... option to make a decision ... about her disease ...

- ... ask whether 'the patient' appreciates what has been done ... the patient might just want to please the caregiver ... frightened ...

- ... think of the situation ... make it your own experience ... useful in new meetings.

- ... concentrate more on the patient's facial expression ...

- ... you could never speculate how a situation could develop ... no grief or sorrow is similar.

Action plan: If it is aroused again what would you do?

- I might interpret the situation in the same way ...

- Think of what I have learnt ... what I have experienced ...I might judge the situation differently.

- You have to be open and receptive to other people's need ...

- ... important to be prepared for difficult nursing situations ... try to find short moments of entire solitude and relaxation ... to get energy ...

- Every situation is different ... you can't copy one patient situation to a new one ... but still you learn something. 


\subsection{Students' Evaluations of the Reflection Process via Works of Art}

From students' written evaluations the students express that they became aware of knowledge that they had never thought of before, and that it was a good way to take a step closer to clinical practice.

The students express $(83 \%$ of $n=98)$ that they get a deeper understanding of the reflection process described in text books. You became aware of that you could learn a lot from fellow students, and you realise that it is not easy to "really" understand a patient. The students also expressed that pictures should be used in other domains of education. The learning model was appreciated because it gave them opportunities to learn from experience.

\subsection{Summary of Results}

Art museum could be regarded as a stimulating environment that nurtured the teaching learning process concerning the reflection process. The students were able to build hypothetical situations around the characters depicted in the painting. They observed and described a great many aspects of the reflection process. Some of the paintings used for the reflection purpose were expressly designed and highly complex works of art. Some stirred negative emotions, but were regarded as interesting to use in the reflection process.

Students evaluations showed that this learning model was appreciated, they thought that it gave them opportunities to learn from experience. They became aware of knowledge that they had never thought of before, and that it was a good way to take a step closer to clinical practice.

\section{DISCUSSION}

The visual art programme is constructed and developed in the light of van Manen's pedagogical model [54]. He stresses that learning is about discovery more than information. The visual art museum formed an ideal opportunity in order to practice van Manen's thoughts about discovery. The students used the paintings as sources of inspiration. They were free to describe how the reflection process could be interpreted when using a painting. In addition, the visual art programme established a basis for a relaxed non-threatening situation. The students perceived a sense of security. A contributing factor to the relaxed situation could be that the picture functioned as a bridge that spanned the gap between the students and the teacher, and created opportunities for a positive and relaxed learning climate. Similar thinking is reported in previous research $[58,59]$.

In the present study art is considered in a wider con- text of art appreciation than the traditional study of History of Art. The painting was pretested and selected in order to provide a starting point for reflection. The aim of the programme was to stimulate discussions about the reflection process. The students' interpretations were looked upon as something separate from the intention of the artist. They were asked to allow the painting to evoke knowledge about the reflection process. The value of this approach was that the students were free to use interpretations independent of the artist's intention [44].

\subsection{Excerpts from Gibbs Five Steps}

When the students were to consider the first step in the reflection process; Feelings: What were you thinking and feeling; they reported on how the depicted person felt through her facial expression and body language. It is exemplified in excerpts like; she is depressed ... her body language and her facial expression ... her situation ...; to understand the patient's feelings without having the same feeling yourself ... empathy is about that ...

In the excerpts from the second step: Evaluation: What was good and/or bad about the experience; several important aspects of reflection are reported about experiences. The students mention intuition, theoretical knowledge and a patients' body language as valuable sources of information. It is exemplified by the following excerpts; It was interesting and useful to try to find out what a patient was thinking ... and worried about ... from her body language; It became clear that you need intuition ... and experience ... not enough with theory ...

The third step: Analysis: What sense can you make of the situation; is exemplified by the excerpt; ... the patient needs to feel that she has some power over the situation ... despite she is at a hospital ... show consideration for the patient. This excerpt points at the important role of the nurse; to give good care and to support the patient about choice of treatment. The nurse has to balance between to give the patient a tool without to take over the role of the patient. This can be seen in the light of the empowerment process. Becoming responsible for your life, establishing goals and priorities are important steps in the empowerment process $[60,61]$.

Conclusion: What else could you have done; the fourth step in the reflection process is exemplified by the following excerpt: You could go deeper into the situation ... reflect over the situation ... collect more information from the "patient"; ... encourage patients to take their own initiative ... stimulate the patient ... give the patient alternative ... option to make a decision ... about her disease. The excerpts point at important aspects of what else they could have done to help the patient. For instance they mention two important aspects in the reflec- 
tion step; be engaged in the situation, and to give the patient alternative. This is in line with Gibbs reflective and professional practice "the capacity to reflect on action so as to engage in a process of continuous learning” [2 p. 21] The ability to reflect is a learned behavior that is cultivated over a period of time, and moves the learner from one experience to a deeper understanding [62].

The fifth step; Action plan: If it is aroused again what would you do? is illustrated by the following excerpts; Think of what I have learnt ... what I have experienced ... I might judge the situation differently; You have to be open and receptive to other people's need; important to be prepared for difficult nursing situations. The excerpts show that the students are aware of that they could learn something from each nursing situation. They reflect over the uniqueness of each nursing situation and the importance of reconsider the situation. According to Dewey awareness of experience plays an important part in the learning process [4].

The excerpt from the five steps in Gibbs' reflection model [2] illustrates how looking at a painting could encourage the students to describe points of view on reflection that could be considered as important. The excerpt is characterized by an emotional as well as a cognitive aspect in the student's reflection. It became obvious that the subject matter showed in the painting influenced both the content and the structure of the reflection process. Gibbs model is associated with learning from experience, and is viewed as an important strategy for health professionals who embrace lifelong learning. Due to the ever changing context of healthcare and the constant growth of medical knowledge, there is a high level of demand on healthcare professionals' expertise.

\subsection{Art in Education}

In several studies art has proven useful in nurse education. Not only literature and poetry, but also visual art and music are all important in nurse education by different means because they develop the students' awareness of their experience [38]. According to Dewey [4] awareness of experience plays an important part in the learning process. In the present study the students express that they became aware of knowledge they had never thought of before. This is in line with previous research that shows that different art forms could be complements to traditional textbooks and rich sources in order to find new ways to understand the patient. Analysing literary texts could be challenging and thought provoking. It helped the student develop understanding of nursing problems that might appear in clinical practice. In several studies art was found to be an important tool in the educational system [15,39]. Different art forms are valuable sources of information to be developed in nursing educa- tion [33]. The result in the present study points in a similar direction, especially in student nurses evaluations.

A disadvantage with the design used in the present study is that it is not a natural situation without having the patient present. Certain amount of spontaneity may be lost. An advantage though is, as expressed in the students' written evaluations, that it was a good way of taking a step closer to clinical practice. The students became aware of that it is not easy to really understand a patient. The reflection process via a painting prepared them for meetings with patients in clinical practice. It is to be assumed that they should be able to apply reflection strategies which are relevant in clinical practice e.g. giving information and support.

\section{CONCLUSION AND IMPLICATIONS}

The present study supported the view that visual art, related to a person's experiences and expectations, is of importance for student nurses when studying the reflection process. It is to be hoped that this study will contribute to the development of visual art museum as a teaching learning milieu in student nurse education. We have to take into consideration the importance the meaning of the teaching learning environment could have for students and teachers. Students and teachers are stimulated in the aesthetic environment, and consequently visual art museums should be regarded as important in the teaching learning process. We must however be cautious about making causal statements from the present study.

\section{REFERENCES}

[1] Gibbs, G. (1981) Teaching students to learn: A studentcentered approach. Open University Press, Buckingham.

[2] Gibbs, G. (1988) Learning by doing: A guide to teaching and learning methods. Further Educational Unit, Oxford Polytechnic, Oxford.

[3] Hirn, Y. (1902) Konstens ursprung: En studie öfver den estetiska värksamhetens psykologiska och sociologiska orsaker. [A study of aesthetical experiences; psychological and sociological causes]. Helsingfors, Söderström.

[4] Dewey, J. (1933) How we think: A restatement of the relation of reflective thinking to the educative process. D.C. Health, Boston.

[5] Dickie, G. (1994) Arts and aesthetic; an institutional analysis. Cornell University Press, London.

[6] Weitz, M. (1976) Art: Who needs it? The Journal of Aesthetic Education, 10, 19-28. doi:10.2307/3332006

[7] Goleman, D. (1996) Emotional intelligence, why it can matter more than IQ. Bloomsbury Publishing, London.

[8] Morgan, R.C. (1998) A sign of beauty. In: Beckley, B., Shapiro, D. Eds., Uncontrollable Beauty, toward a New Aesthetics, Allworth Press, New York, 75-82.

[9] Martin, A. (1998) Beauty is the mystery of life. In: Beck- 
ley, B. and Shapiro, D. Eds., Uncontrollable Beauty, toward a New Aesthetics, Allworth Press, New York, 399402.

[10] Hillman, J. (1998) The practice of beauty. In: Beckley, B. and Shapiro, D. Eds, Uncontrollable Beauty, toward a New Aesthetics. Allworth Press, New York, 261-274.

[11] Khatchadourian, H. (1980) Humanistic functioning of the arts today. Journal of Aesthetic Education, 14, 11-21. doi:10.2307/3332474

[12] Woodhams, L. (1995) The arts in health: Implication for artistic and health practice, policy development, education and training. Australian Journal of Primary HealthInterchange, 1, 39-41.

[13] Wikström, B.M. (2002) Intuition and visual art: Student nurses' projection into experiences of elderly women. The Australian Journal of Holistic Nursing, 9, 24-31.

[14] Wikström, B.M. (2000) Visual art dialogues with elderly persons: Effect on perceived life situation. Journal of Nursing Management, 8, 31-37. doi:10.1046/j.1365-2834.2000.00154.x

[15] Wikström, B.M. (2002) Aging perceived through visual art observations. Geriatric Nursing, 21, 300-303.

[16] Wikström, B.M., Theorell, T. and Sandström, S. (1993) Medical health and emotional effects of art stimulation in old age. Psychotherapy and Psychosomatics, 60, 195-206. doi: $10.1159 / 000288693$

[17] Wikström, B.M., Ekvall, G. and Sandström, S. (1994) Stimulating the creativity of elderly institutionalized women through works of art. Creativity Research Journal, 7, 171-182. doi:10.1080/10400419409534522

[18] Bygren, L.O., Konlaan, B.B. and Johansson, S.E. (1996) Attendance at cultural events, reading books or periodicals, and making music or singing in choir as determinants for survival: Swedish interview survey of living conditions. British Medical Journal, 313, 1577-1580. doi:10.1136/bmj.313.7072.1577

[19] Konlaan, B.B. (2000) Attendance at cultural events physical exercise and health: A randomized controlled study. Public Health, 114, 316-319.

[20] Lidsay, S. (1997) Music in hospitals: The best medicine in the world. In: Kaye, C. and Blee, T., Eds., The Arts in Health Care, a Palette of Possibilities, MacMillan Press, Hampshire, 28-33.

[21] Ryan, E.A. (1994) The use of music distraction on pain in hospitalized school-aged children. In: Funk, S.G., Tornqvist, E.M., Champagne, M.T., Copp, L.A. and Wiese, R.A., Eds., Management of Pain, Fatigue and Nausea, MacMillan, New York, 101-105.

[22] Angus, J.E. and Faux, S. (1994) The effect of music on adult postoperative patients' pain during nursing procedure. In: Funk, S.G., Tornqvist, E.M. and Champagne, M.T., Eds., Management of Pain, Fatigue and Nausea, MacMillan, New York, 136-142.

[23] Bratt-Rawden, K. and Tellnes, G. (2011) How music may promote healthy behaviour. Scandinavian Journal of Public Health, 39, 113-120. doi:10.1177/1403494810393555

[24] Grape, C., Theorell, T., Wikström, B.M. and Ekman, R.
(2009) Choir singing and fibrinogen, VEGF, cholecystokinin and motilin in IBS patients. Medical Hypotheses, 72, 223-224. doi:10.1016/j.mehy.2008.09.019

[25] Götell, E., Brown, S. and Ekman, S.L. (2009) The influence of a caregiver singing and background music on vocally expressed emotions and moods in dementia care, a qualitative analysis. International Journal of Nursing Studies, 46, 422-430. doi:10.1016/j.ijnurstu.2007.11.001

[26] Götell, E., Brown, S. and Ekmam S.L. (2009) Caregiverassisted music events in psychogeriatric care. Journal of Psychiatric and Mental Health Nursing, 7, 119-125.

[27] Johnsson, J.E. (2003) The use of music to promote sleep in old woman. Journal of Community Health Nursing, 20 , 27-35.

[28] Lai, H. and Good, M. (2005) Music improves sleep quality in older adults. Journal Medical, 49, 34-244.

[29] Suter, E. and Baylin, D. (2007) Chosing art as a complement to healing. Applied Nursing Research, 20, 32-38. doi:10.1016/j.apnr.2005.11.004

[30] Geimer-Flanders, J. (2009) Creating a healing environment: Rational and research overview. Cleveland Clinic Journal of Medicine, 76, 566-569. doi:10.3949/ccjm.76.s2.13

[31] Bruderle, E.R. and Valiga, TM. (1994) Integrating the arts and humanities into nursing education. In: Chinn, P.L. and Watson, M.J., Eds., Art \& Aesthetics in Nursing, National League for Nursing, New York, 117-144.

[32] Breslin, E.T. (1996) Aesthetic methods as a means of knowing for nursing. Issues in Mental Health Nursing, 17, 503-505. doi:10.3109/01612849609006528

[33] Mohr, W.K. (1995) Integrating aesthetics into nursing, literature as a suggested modality. Archives of Psychiatric Nursing, 6, 365-372. doi:10.1016/S0883-9417(95)80060-3

[34] Darbyshire, P. (1994) Understanding caring through arts and humanities: A medical/nursing humanities approach to promote alternative experiences of thinking and learning. Journal of Advanced Nursing, 19, 856-863. doi:10.1111/j.1365-2648.1994.tb01161.x

[35] Wikström, B.M. and Svidén, G. (2005) Facial expressions in paintings as perceived by the student nurse. Australian Journal of Holistic Nursing, 12, 5-12.

[36] Wikström, B.M. (2000) The development of observational competence through identification of nursing care patterns in "The Sickbed", a work of art by Lena Cronqvist. Journal of Inter Professional Care, 14, 181-194.

[37] Wikström, B.M. (2000) Nursing education at an art gallery. Journal of Nursing Scholarship, 32, 197-199.

[38] Wikström, B.M. (2001) Visual art and non-verbal sensitivity: A teaching-learning program in nurse education. Australian Journal of Primary Health, 7, 26-30. doi:10.1071/PY01042

[39] Wikström, B.M. (2001) Works of art dialogues: An educational technique by which students discover personal knowledge of empathy. International Journal of Nursing Practice, 7, 24-29. 


\section{doi:10.1046/j.1440-172x.2001.00248.x}

[40] Wikström, B.M. (2003) A picture of works of art as an empathy teaching strategy in nurse education complementary to theoretical knowledge. Journal of Professional Nursing, 19, 49-54. doi:10.1053/jpnu.2003.5

[41] Koitan, M. (1996) Aesthetics in nursing practice and education. Issue in Mental Health Nursing, 17, 529-539. doi:10.3109/01612849609006531

[42] Bardes, L.B., Gillers, D. and Herman, A.E. (2001) Learning to look: Developing clinical observational skills at an art museum. Medical Education, 35, 1157-1161. doi:10.1046/j.1365-2923.2001.01088.x

[43] Weir, H. (2010) You don't have to like them: Art, Tate Modern and learning. Journal of Applied Arts and Health, 1, 93-100. doi:10.1386/jaah.1.1.93/1

[44] Wikström, B.M. (2011) Works of art as a pedagogical tool: An alternative approach to education. Creative Nursing, 17, 183-194.

[45] Hedly, V., Wikström, B.M., Gunnarsson, E. and Sjöqvist, K. (1994) Individualized activities as a motivating factor in long-term care. Geriatric Nursing, 15, 246-249. doi:10.1016/S0197-4572(09)90077-5

[46] Peszek, M.E. (2009) Sacred art as a pedagogical tool. An experiment from Rome: Caravaggio's “The Calling of Saint Matthew.” Adoremus, 15, 3. http://www.adoremus.org/05091Peszek.html.

[47] Blomqvist, L., Pitkälä, K. and Routasalo, P. (2007) Images of loneliness: Using art as an educational method in professional training. Journal of Continuing Education in Nursing, 38, 89-93.

[48] Berlyne, D.E. (1971) Aesthetics and psychobiology. Appleton-Century-Crofts, New York.

[49] Sandström, S. (1977) A common taste in art, an experimental attempt. Aris, Lund.

[50] Wikström, B.M. (2002) Social interaction associated with visual art dialogs: A controlled intervention study. Aging \& Mental Health Issue, 6, 80-85.
[51] Sandström, S. (1997) Intuition och åskådlighet [Intuition and precision]. Carlssons Förlag, Stockholm.

[52] Wikström, B.M., Theorell, T. and Sandström, S. (1992) Psycho physiological effects of stimulation with pictures of works of art in old age. International Journal of Psychosomatics, 39, 68-75.

[53] Morse, J.M. and Field, P. (1996) Nursing research: The application of qualitative approaches. Chapman \& Hill, London.

[54] Van Manen, M. (1990) Researching lived experience: Human science for an action sensitive pedagogy. The University of Western Ontario, Ontario.

[55] Kvale, S. (1989) Issues of validity in qualitative research. Studentlitteratur, Lund.

[56] Hermerén, G. (1986) Kunskapens pris. Forskningsetiska problem och principer i humaniora och samhällsvetenskap [The cost of knowledge. Research ethical problems in humanities and social science]. Stockholm.

[57] Williams, R.J. (2008) The declaration of Helsinki and Public Health. Bulletin of the World Health Organisation, 86, 650-651. doi:10.2471/BLT.08.050955

[58] Bevis, E. and Murray, J. (1990) The essence of the curriculum revolution. Emancipatory teaching. Journal of Nursing Education, 29, 326-331.

[59] Diekelmann, N. (1995) Reawakening thinking: Is traditional pedagogy nearing completion? Journal of Nursing Education, 34, 195-196.

[60] Aujoulat, I., D’hoore, W. and Deccache. A. (2007) Patient empowerment in theory and practice: Polysemy or cacophony? Patient Education and Counselling, 66, 1320. doi:10.1016/j.pec.2006.09.008

[61] White, T.A. (1989) Empowering yourself, empowering the patients. In course syllabus: New approaches to patient care in diabetes. University of Michigan, Ann Arbor, Michigan, 1989.

[62] Dewey. J. (1934) Art as experience. Capricorn Books, G.P. Putnam's Sons, New York. 